\title{
Raspberry Pi in Attendance Tracking System
}

\author{
Sanam Kazi \\ Assistant Professor, \\ Department of \\ Information Technology, \\ M.H.Saboo Siddik \\ College of Engineering,
}

\author{
Farhan Pasha \\ Student (B.E), \\ Department of \\ Information Technology, \\ M.H. Saboo Siddik \\ College of Engineering, \\ Mumbai,India
}

\author{
Farzana Gorme \\ Student (B.E) \\ Department of \\ Information Technology, \\ M.H. Saboo Siddik \\ College of Engineering, \\ Mumbai,India
}

\author{
Hozefa Bata \\ Student (B.E), \\ Department of \\ Information Technology, \\ M.H. Saboo Siddik \\ College of Engineering, \\ Mumbai,India
}

\begin{abstract}
In the recent years there has been rise in the number of application based on raspberry pi and RFID (Radio Frequency Identification) cards and has been successfully applied to the attendance tracking system. This project will be used for automatically managing the student attendance process for any given learning organization. This system facilitates automation in terms of aggregating the number of head count and is managed completely by an automated system. In this paper, an attempt is made to solve the current problem of inconsistency, time consumption and also elimination of paper work. The current system has various flaws like class attendance are not secure, time consuming and it can be prone to errors if it is taken verbally or visually. There also persists the issue of proxy as well as a nuisance is created when the attendance is taken manually which ultimately ruins the discipline. There are many ways in which this is performed today such as a sign up sheet which is passed around, attendance taken verbally, or sometimes not taken at all. All of these will be eliminated with the implementation of the system using Raspberry pi. The configuration of the project will consist of a Raspberry pi with an attached RFID card and RFID reader. By using raspberry pi an accurate process will be maintained which will take attendance automatically when the student enters the room. Each student will be required to have their student ID card (RFID card) which will ensure consistency. The Attendance Tracking system will rely heavily on computer hardware and its backend database and an RFID card which does all the processing tasks when the system is interconnected and made ready for implementation. This system facilitates automation in terms of aggregating the number of head count and is managed completely by an automated system.
\end{abstract}

\section{Keywords}

Application of raspberry pi, raspberry pi model, reports, RFID reader, Simplified Attendance Tracking.

\section{INTRODUCTION}

Attendance is for primarily used to maintain the record of students present in the school or colleges which serves as a basic requirement for the discipline and for providing quality education in an organization. Traditional method used for tracking attendance is by calling names or roll number of each student and then marking present or absent accordingly. There are various flaws in the existing system of RFID as well. Apart from inconsistency and time consumption, it involves lots of paper work and possibly leads to personal error in tracking the attendance. There arises a need for solving all these various problems. With the evolution of technology various new methods are evolving one of them is Attendance tracking by means of using Raspberry pi. Raspberry Pi is a dynamic microcontroller that is capable of just about a computer is. No matter how small the scope of the system may be, it helps saving time by performing an automated and more precise process of taking attendance. It does not add to any more complications to an organization rather simplifies the task and makes less use of resources as not all Students have to be gathered around in a room to take attendance. This integration will allow for an automated method to be used for Schools and Universities that need to take an accurate attendance of students in each of their classes. The configuration of the project will consist of a Raspberry pi with an attached RFID card and RFID reader. The RFID device serves the same purpose as a bar code or a magnetic strip on the back of a credit card or ATM card, just as a bar code or magnetic strip must be scanned to get the information, the RFID device must be scanned to retrieve the information which is unique [1].Each student will be required to have their student ID card (RFID card) on their person when entering the classroom. The backend data will be managed by custom software. This project is initially intended for managing the student attendance for a school, but will be designed such that it can support attendance requirement tracking for any given organization. The Attendance Tracking system will enable instructors and students to get down to the business of learning as quickly as possible without wasting time with the manual process of taking attendance.

\section{PROPOSED SYSTEM}

\subsection{System Overview}

The proposed system provides alternative to the existing problems. The manual business process of taking class attendance at a university is the scope of the project. This inconsistent process is the area where the proposed system will add benefit to an organization. The automation of this manual process will allow for more class time to be spent on teaching and less on this mandatory process. The opportunity in this project is the ability to start classes on time without delay. The aim of the project is to dedicate more time for the learning.

The proposed system will process the following types of data:

\section{Student information}

This will include specific information in regards to each student such as, student id, Name (First, Middle, and Last).

\section{Class Enrollment information}

This will include the list of registered students for a specific class.

\section{Reports}

Reports can be generated for the organization, instructors, as well as students interested in their personal attendance; how many times have they missed class, or been late. 
The proposed system will have various interfaces such as users, other interfacing systems, as well as hardware and software. They are broken down as follows:

\subsubsection{User Interaction:}

2.1.1.1 Students (normal operation) - The interface for students will be through and RFID enabled student ID card[2]. This interface for the student will be seamless. They only need to enter the room to be counted as present in the class.

2.1.1.2 Students (reporting operation) - Students would interface with the system via a Web based application. The ability to view their own attendance data will be controlled via account privileges.

2.1.1.3 Instructors (normal operation) - The system will be configurable to run automatically. For example, an instructor of a class would not need to do anything beyond clicking submit, when ready, to have the attendance automatically taken.

2.1.1.4. Instructors (reporting operation) - Administrators of the system would interface with the system via a web based application. It will enable the ability to view, adjust/update, and submit a class attendance. As with the students, access will be controlled via account privileges.

Interface with Locations: Schools, companies, organizations and other offices -- Since the Attendance tracking system is a location based system using a RFID and Raspberry Pi [3], the application can be accessed using either a PC or MAC. In addition, a tablet can be used since the database and reports will automatically configure to the screen size. The constraint will be that the application can only be accessed using a Linux system [4] (Ubuntu). This will limit OS breach vulnerabilities. Interface with Other Systems: The Attendance Tracking system will interface with RFID of user's unique verification card to deploy the application. In addition, the system will also interface with SQL Server to query data needed for the application. Data will include person's attendance history, logging in and login out timings, followup, and other future scope services.

Interaction with other systems: There is no need for other systems to be integrated with our system; our system itself is internally integrated by different technologies ranging from hardware (RFID, Raspberry Pi) to software (backend database system).

\subsubsection{System Interface:}

\subsubsection{Locations served by the system}

The locations served by the system are local in nature. The University personnel and students with valid credentials would be able to access system via the University's intranet.

\subsubsection{Users served by system}

It could be used for organizations ranging from handful to thousands of employees. It can be applied in any field that needs an automated attendance management system

\subsubsection{Interaction with other systems}

There is no need for other systems to be integrated with our system; our system itself is internally integrated by different technologies ranging from hardware (RFID, Raspberry Pi) to software (backend database system).

\subsection{System Design}

The Attendance Tracking system data will be stored in a database on a local server, inside the university's network. Data from the database will be retrieved via the application, which will provide a graphical user interface using web technology. The Raspberry Pi's will be limited to running the Linux OS [5] platform while the application can be deployed using a laptop or tablet, regardless of operating system. Only those employed by, or are a registered student at, the University may access and use the system. Employees and Students of the university will be provided permission to the system from the University itself. The University may forbid a person from using the system if required.

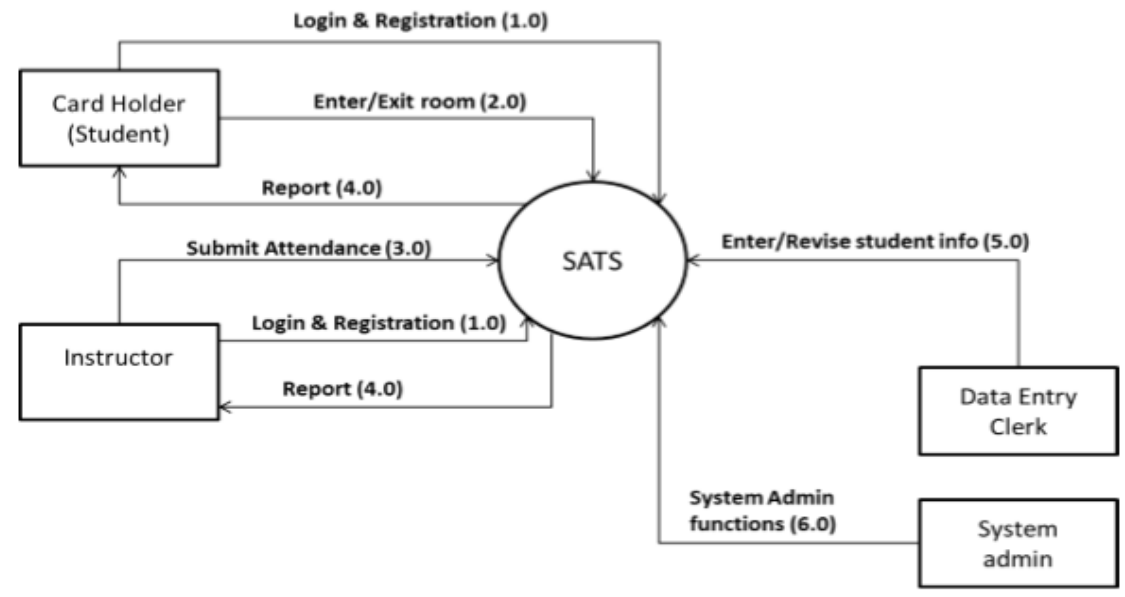

Fig 1: Context Diagram

\subsection{System Architecture}

The architecture will incorporate RFID technology to improve the process of taking attendance in a University setting. The design will employ RFID cards as well as RFID readers to track persons entering and exiting the room. This data will then be automatically entered into a database from which data can be viewed and reports can be run. A dedicated database server will be employed to maintain the Attendance Tracking database. Network connectivity will exist between the RFID readers and this dedicated database server. User, either administrator or students, can access system via web for reporting purposes. 


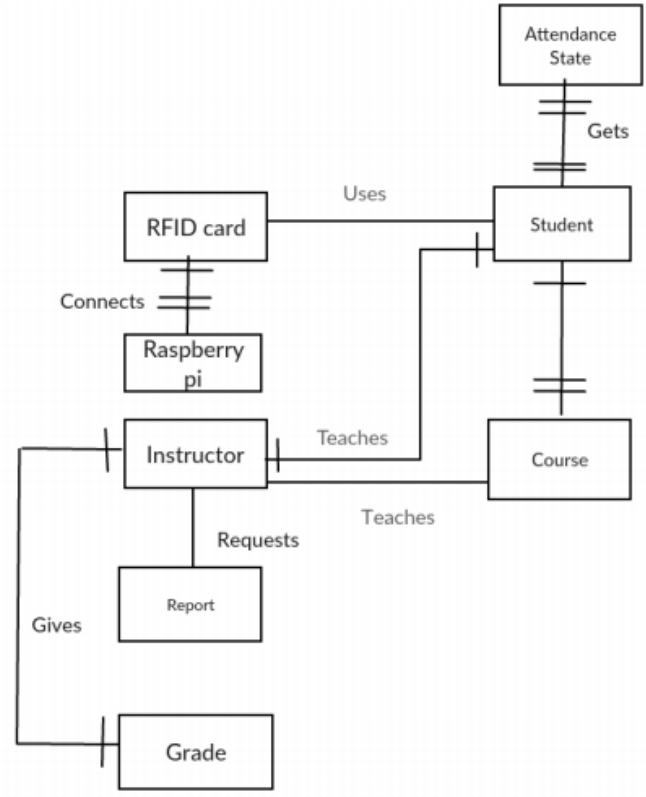

Fig 2: Context Model

\section{REQUIREMENT ANALYSIS}

\subsection{Functional Requirements}

1) Instructors, Administrators, and Students must be able to register to use the system.

2) Instructors, Administrators, and Students must be authorized to login to the system based on user credentials.

3) The system must be able to lock out a user and track failed attempts to login.

4) The system must able to perform room entry/exit transactions in real time

5) Instructor's ability to set "Late" thresholds for their respective class.

6) A student must be able to view their attendance record for a specific class.

7) A student must be able to view their attendance record for a specific Semester.

8) Access to the system data must be done via a user interface.

9) The system must allow instructors to submit the class Attendance for a specific class.

10) The system must allow for auto-submit of attendance.

\subsection{Non Functional Requirements}

1) The system must be available for reporting purposes at all times.

2) The Attendance tracking system needs to be delivered on time.

3) Training plan is required.

4) Help is available from the user interface.

\subsection{Problems in Existing System}

1. Current process for taking attendance is time consuming.

2. Current process for taking attendance inconsistent and inaccurate.

3. 3 It is not secure and confidential.

4. There is no proper management of reports.

\subsection{Advantages of Proposed System}

1) It will save time, manual efforts and more over majority of the costs involved in implementing this system are one-time costs which could be considered as an advantage over the traditional procedure.

2) Attendance tracking is completely customizable and using the Raspberry Pie(manual chip interface) [6] all the students entering the classroom with a valid RFID card will be automatically marked present and there attendance will be marked in the database for that particular class on that particular day.

3) The Attendance tracking is very much technically feasible because it involves automation and students and the professor would practically mark their own attendance by just walking across the Raspberry Pie(a chip interface) carrying a valid RFID card[7].

4) The information is passed to the database connected to Raspberry $\mathrm{Pi}$ system which will ensure complete accuracy of the data.

5) Records are kept safe and confidential.

6) Reports to be generated after brief interval of time, or monthly records can be maintained and can also be exported to other inter organizational departments in .xls format to improve accuracy.

7) Each Student is able to generate record for particular class.

\section{IMPLEMENTATION}

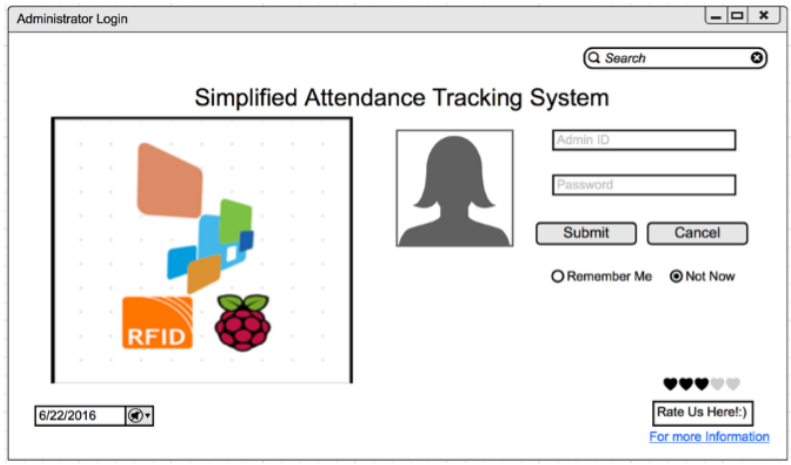

Fig 3: Login Screen

Figure 3 represents the Login screen wherein the Administrator will enter his/her credentials in order to log-in to the database. It the user/administrator enters any invalid ID/password, the system will inform the user of invalid credentials and will deny access 


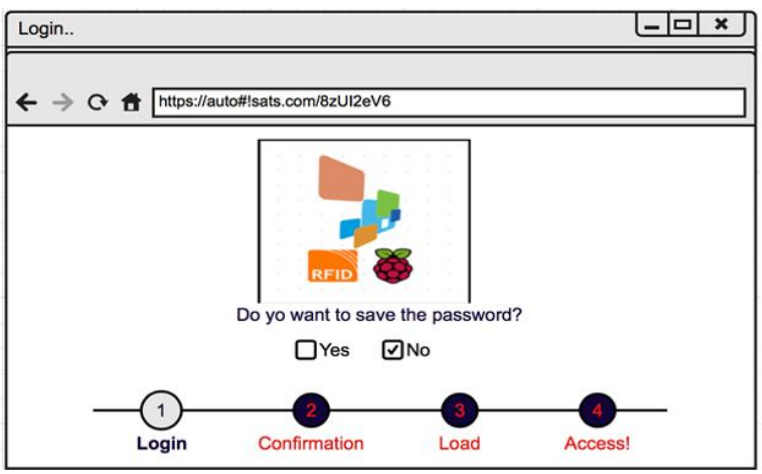

Fig 4: Password Saving Screen

Figure 4 represents password saving screen the wherein, the system will ask the user/administrator to save the password, if the user clicks yes, the password will be saved in the cache memory and he won't be required to re-enter the password every time he tries to enter the database.

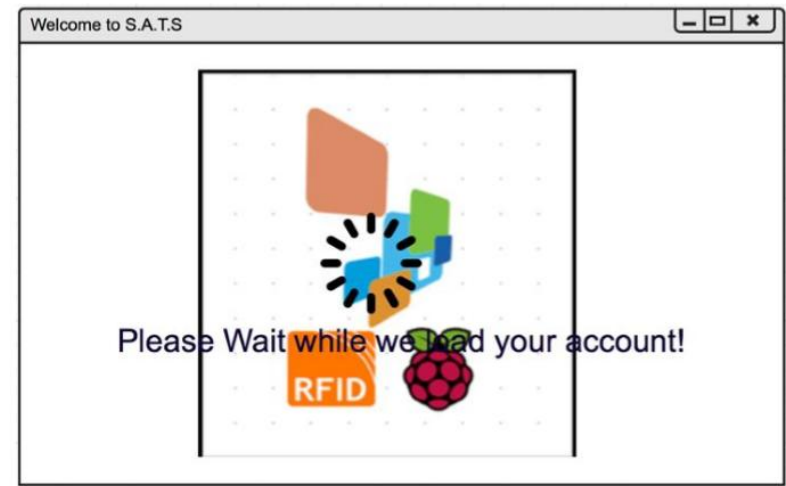

Fig 5: Accessing System Screen

Figure 5 represents that after entering the credentials, the system will require a couple of moments to extract, transform $\&$ load the data onto the database and then the administrator will be granted access to the actual database.

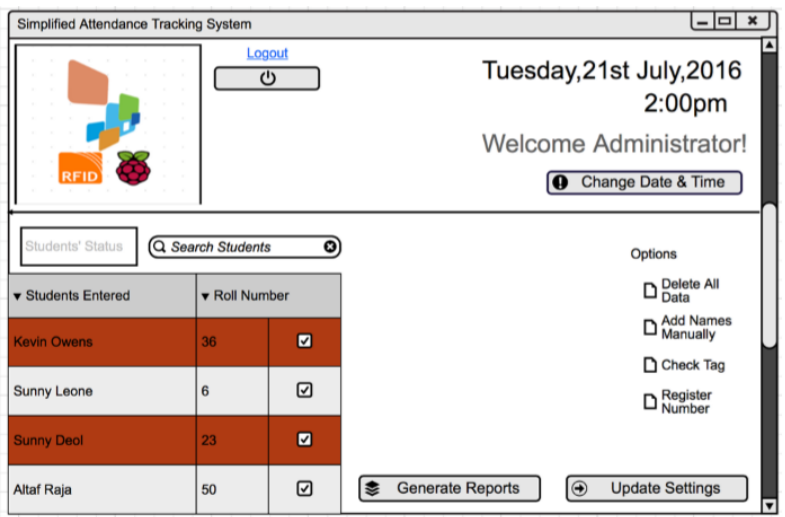

Fig 6: Home Screen of the System
Figure 6 represents the actual home screen of the S.A.T system containing a table on the bottom left corner of the screen showing the students' status which will be constantly updating as and when any student enters the classroom and the administrator can also generate hourly, daily or weekly reports based on the organizational requirement.

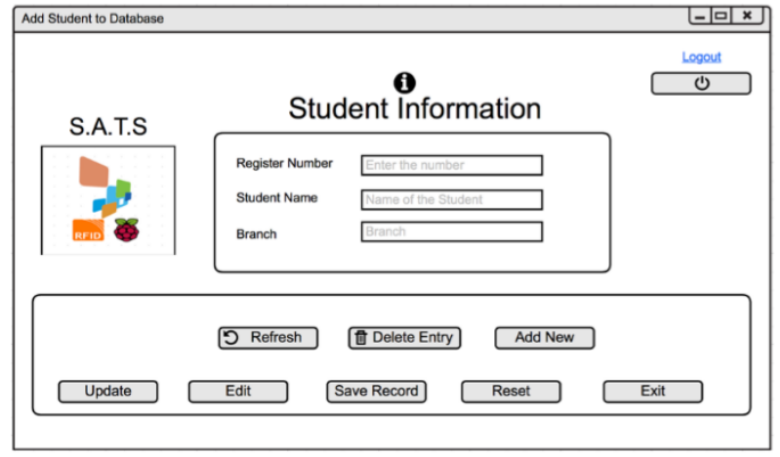

Fig 7: Information Detail Screen

Figure 7 represents that the administrator can also add a particular student to the database in case there is any new admission. The above screen manifests the student information page wherein the administrator can create a new record by entering the register number, student name \& the branch of the student. Many other functions can also be performed on the student records such as adding more records, deleting the existing entry, resetting previous student entries, etc.

\section{FUTURE SCOPE}

In terms of future scope, it is expected to provide more details report and a complete summary with respect to an organizations employee's attendance tracking and enables more privileges for the administrator. It is expected to save time and be more precise in terms of its functional requirement and also to eliminate the vital need and saving time when it comes to tracking attendance.

\section{ANALYSE PROBLEMS}

\subsection{Cause and Effect Analysis \& System Improvement Objectives}

The following table depicts the Cause and Effect Analysis and the result for the proposed system as well as the System Improvement Objectives. The following analysis is based on the initial analysis of the problem domain. These problems were reviewed and the specific causes and effects are documented. The System Improvement Objective Each problem has been evaluated to determine the cause and effects. The three key problems are as follows:

1) Time consuming

2) Inconsistent

3) Erroneous 
Table 1 Cause and Effect Analysis \& System Improvement Objectives

\begin{tabular}{|c|c|c|c|}
\hline \multicolumn{2}{|c|}{ Cause and Effect Analysis } & \multicolumn{2}{|c|}{ System Improvement Objectives } \\
\hline Problems/Opportunity & Cause and Effects & System Objective & System Constraints \\
\hline $\begin{array}{l}\text { Current process for taking } \\
\text { attendance is time consuming. }\end{array}$ & $\begin{array}{l}\text { - The attendance process is } \\
\text { taken manually by passing } \\
\text { around a sign in sheet to the } \\
\text { whole class. This takes a lot of } \\
\text { time which impedes the start } \\
\text { time for the class. } \\
\text { - The attendance process is } \\
\text { taken manually with the use of } \\
\text { blackboard. } \\
\text { - The attendance process is } \\
\text { taken manually in some other } \\
\text { fashion. Again, time } \\
\text { consuming and holds up start } \\
\text { time for class. }\end{array}$ & $\begin{array}{l}\text { To enable automation of the } \\
\text { process. The system can be } \\
\text { setup to be completed } \\
\text { automated. }\end{array}$ & $\begin{array}{l}\text { The time to complete the } \\
\text { process cannot take any longer } \\
\text { than it does today. }\end{array}$ \\
\hline $\begin{array}{l}\text { Current process for taking } \\
\text { attendance is inconsistent. }\end{array}$ & $\begin{array}{l}\text { - Many instructors perform the } \\
\text { process in different manners. } \\
\text { The consistency and accuracy } \\
\text { of the data is at risk based on } \\
\text { this inconsistency. } \\
\text { - The current system allows for } \\
\text { various methods to be used. } \\
\text { This flexibility needs to be } \\
\text { controlled with the new system } \\
\text { to ensure consistency of the } \\
\text { process. }\end{array}$ & $\begin{array}{l}\text { The system must limit the } \\
\text { flexibility around the } \\
\text { attendance taking process. }\end{array}$ & $\begin{array}{l}\text { There must be an override for } \\
\text { an administrator of the system } \\
\text { for special exceptions. }\end{array}$ \\
\hline $\begin{array}{l}\text { Current process for taking } \\
\text { attendance can be inaccurate. }\end{array}$ & $\begin{array}{l}\text { The various means by which } \\
\text { the attendance data is captured, } \\
\text { leads to inaccuracies within the } \\
\text { data. A sign in sheet needs to } \\
\text { be interpreted by someone and } \\
\text { entered manually into the } \\
\text { system. }\end{array}$ & $\begin{array}{l}\text { The system must ensure } \\
\text { complete accuracy of the data } \\
\text { related to class attendance. }\end{array}$ & $\begin{array}{l}\text { The system will still be subject } \\
\text { to instructors making errors by } \\
\text { manipulating the attendance } \\
\text { prior to submitting (if manual } \\
\text { submit is the method set). }\end{array}$ \\
\hline
\end{tabular}

\section{CONCLUSION}

The Attendance Tracking will serve as a useful approach to automate the system and hence will prove cost effective, more accurate and provide ease of implementation and use, and will slowly diminish the need of the un-conventional method as well as will help to eliminate paper work. Further implementing the Attendance tracking will certainly save a lot of time because of the computerization and the user friendly interfaces involved which will allow the professors to invest all the time in teaching rather than carrying out the manual attendance marking procedure. by reducing the chaos in the learning organization and hence will improve the accuracy of the system. Confidentiality of data is also achieved. Thus we have achieved to develop a reliable develop a reliable and efficient attendance tracking system using Raspberry pi which is consistent, non-erroneous and accurate[8].

\section{REFERENCES}

[1] RFID Technology Based Attendance Management System Sumita Nainan, Romin Parekh, Tanvi Shah.
[2] L.N.Gumilyov Eurasian National University, "Attendance Control systems based on the RFID Technology.

[3] "Proposed Automated Students Attendance Management System Using Raspberry Pi And NFC", International Journal of Research in Computer Information Technology, Vol. 1, Issue 1, 2015.

[4] Implementation of Student Attendance System Sumita using RFID Technology, Longe O.O.(2009).

[5] Arch Linux Arm :Coding the pi With Linux.

[6] Gadget Master - Electronics Weekly; 12/12/2012, Issue 2531, p10 The article presents a blog regarding the use of clocks as theme on the new-Lego based Mindstormspowered variant, offers brief information on the Beagle Embedded Starter Kit from Liquid ware and the Raspberry Pi competition.

[7] K.Domdouzis, B Kumar and C Anumba, "Radio Frequency Identification (RFID) applications: A brief introduction.", Advanced Engineering Informatic".

[8] Shailendra, Manjot Singh, Md. Alam Khan, Vikram Singh, Avinash Patil , Sushma Wadar, "Attendance Management System". 